\title{
Block allotransplantation of both lungs with pulmonary trunk and left atrium in dogs
}

\author{
P. VANDERHOEFT, A. DUBOIS, N. LAUVAU, \\ PH. DE FRANCQUEN, Y. CARPENTIER, P. ROCMANS, \\ R. NELSON,S. KA U F M A , L. BRICKMAN,A. G Y H RA, \\ and P. ECTORS
}

Department of Surgery, St. Pierre Hospital, Free University of Brussels, Belgium

\begin{abstract}
Eleven dogs received a double-lung-block allotransplantation under cardiopulmonary bypass. Six dogs survived over one hour with spontaneous breathing and normal right ventricular pressures. Postoperative blood gases and pressures are given for six animals. These data show a fall in systemic blood pressure and arterial oxygen partial pressure, a rise in $\mathrm{PCO}_{2}$, and no change in $\mathrm{pH}$ after completion of transplantation. Causes of death were haemorrhage (7), inadequate cardiopulmonary bypass (2), early anoxic heart lesion (1), and post-perfusion low output syndrome (1).
\end{abstract}

In 1969 we reported the dangers of unilateral pulmonary transplantation in man (Vanderhoeft et al., 1969). Transplantation of a normal left lung in a patient with a remaining emphysematous and infected right lung resulted in cross infection and fatal maldistribution in ventilation-perfusion ratios between the two lungs (Vanderhoeft et al., 1971). Others have since recognized this maldistribution which had not been anticipated from animal experimentation (Stevens et al., 1970; Wildevuur and Benfield, 1970). We therefore recommended bilateral pneumonectomy before pulmonary transplantation for terminal respiratory failure. Since 1957 many procedures for one-stage bilateral transplantation have been investigated in both animal and man (Demikhov, 1949; Longmore et al., 1969; Lower, Stofer, Hurley, and Shumway, 1961; Vuillard et al., 1969; Veith, Sinha, Torres, and Richards, 1971). The purpose of this preliminary communication is to report our experience with transplantation of a double-lung-block under cardiopulmonary bypass.

\section{METHODS}

Eleven dogs, average weight $30 \mathrm{~kg}$, underwent 'en bloc' allotransplantation of both lungs from unrelated donors of the same weight. The surgical technique is briefly described; complementary details have been reported elsewhere (Vanderhoeft et al., 1970a). The animal is anaesthetized with nembutal (Abbott Laboratory, Chicago, U.S.A.) and a spirogram is recorded.
Intermittent positive pressure breathing is instituted. Catheters are inserted into the femoral artery, right ventricle, and vena cava for continuous pressure recordings and blood gases. A right thoracotomy is performed through the fifth interspace and the right lung is removed. Cardiopulmonary bypass is instituted using a Temptrol oxygenator (Bentley Laboratory, Santa Ana, California, U.S.A.) and Sarns roller pumps, and the left lung is removed through the mediastinum (Fig. 1).

The donor lungs with left atrium and pulmonary trunk are harvested 'en bloc' through a median sternotomy after removal of the heart (Fig. 2). Torsions are avoided by keeping the carina intact and by suturing the lobes together in the inflated state. The lungs are cooled by perfusion with $500 \mathrm{ml}$ of heparinized Ringer's lactate at $4^{\circ} \mathrm{C}$. The double-lung-block is transferred to the recipient, the left lung being inserted through the mediastinum and inflated to fit the left hemithorax. Anastomoses are done in the following sequence: pulmonary trunk, left atrium, and left and right bronchi. The heart is defibrillated if required and cardiopulmonary bypass is discontinued. Protamine is given in a dose equal to one and a half the dose of heparin used for cardiopulmonary bypass. The thorax is closed and a postoperative spirogram is recorded.

\section{RESULTS}

The overall results are given in Table I. In 10 animals, the heart sustained circulation after cessation of cardiopulmonary bypass; in one, it failed immediately. Six dogs survived over one hour and breathed spontaneously. Haemorrhage caused the 


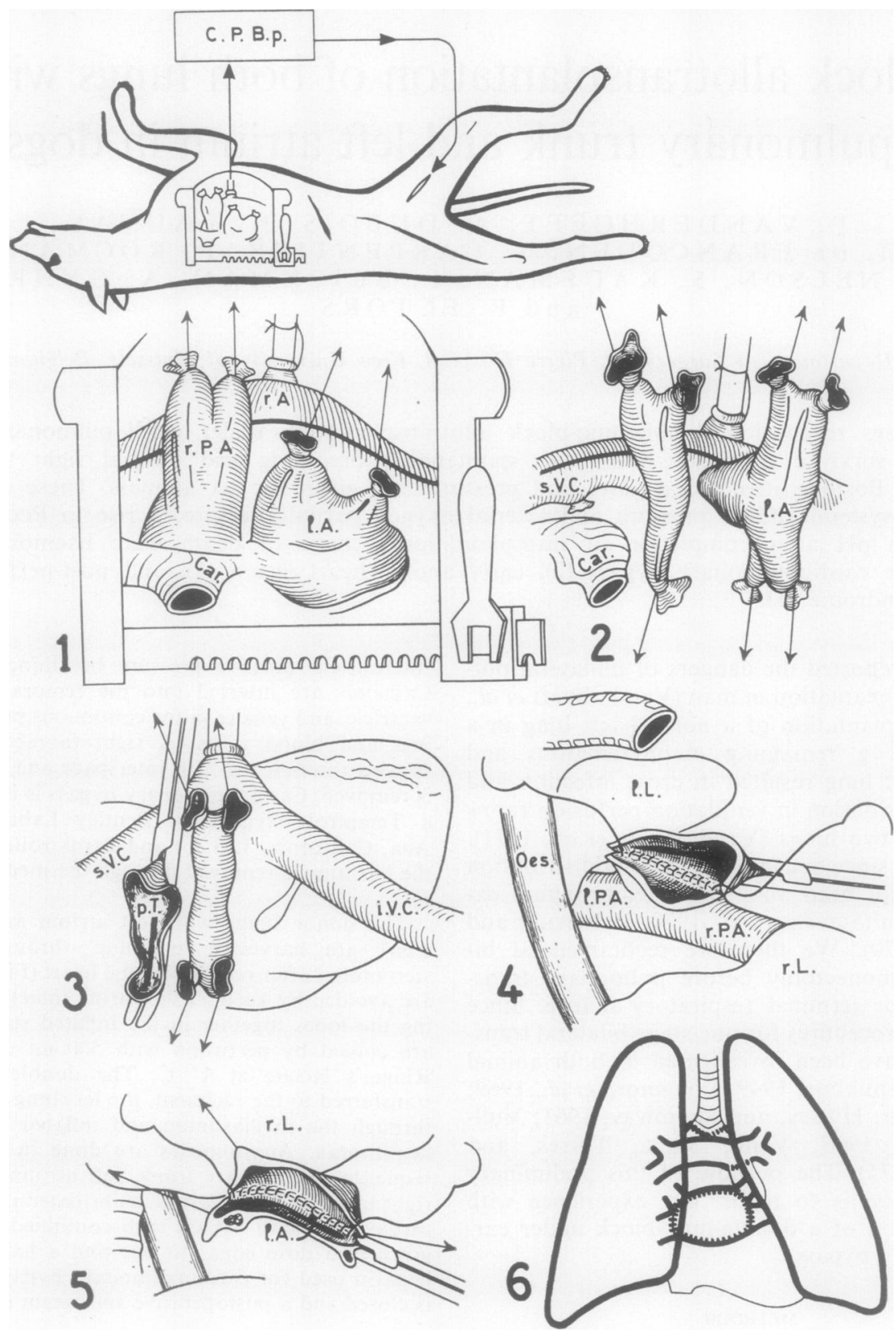

FIG. 1. Recipient of double-lung-block transplantation. (1) Right lung $(r L)$ resected. Animal placed on cardiopulmonary bypass (CPBp). (2 and 3) Left lung (IL) resected from behind heart, leaving carina (Car), pulmonary arteries $(P A)$ and trunk $(p T)$ and left atrium (lA). (4 and 5) Arterial and atrial anastomoses of donor block. (6) End result after anastomoses of bronchi. SVC and IVC=superior and inferior venae cavae; Oes=oesophagus. 
T A B L E I

DATA ON 11 DOUBLE-LUNG-BLOCK TRANSPLANTATIONS

\begin{tabular}{|c|c|c|c|c|c|}
\hline \multirow{2}{*}{ Dog } & \multicolumn{2}{|c|}{ Cardiopulmonary Bypass } & \multirow{2}{*}{$\begin{array}{l}\text { Ischaemia of Transplant } \\
\text { (hr) }\end{array}$} & \multirow[b]{2}{*}{$\begin{array}{l}\text { Survival of Recipient } \\
\text { (hr) }\end{array}$} & \multirow[b]{2}{*}{ Cause of Death } \\
\hline & $\begin{array}{c}\text { Duration } \\
\text { (hr) }\end{array}$ & $\underset{(\mathrm{ml} / \mathrm{kg} / \mathrm{min})}{\text { Flow }}$ & & & \\
\hline $\begin{array}{l}61 \\
62 \\
64 \\
65 \\
66 \\
67 \\
72 \\
73 \\
74 \\
75 \\
76\end{array}$ & $\begin{array}{l}3 \\
3 \frac{8}{4} \\
2 \frac{1}{4} \\
2 \frac{1}{4} \\
2 \frac{3}{3} \\
3 \frac{1}{8} \\
2 \frac{1}{2} \\
2 \\
1 \frac{9}{4} \\
2 \frac{1}{2} \\
1 \frac{8}{4}\end{array}$ & $\begin{array}{l}? \\
0 / 50 \\
60 \\
30 / 60 \\
65 \\
75 \\
55 \\
90 \\
85 \\
95 \\
85\end{array}$ & $\begin{array}{l}1 \frac{1}{8} \\
1 \frac{1}{8} \\
1 \frac{1}{5} \\
1 \frac{1}{2} \\
1 \frac{1}{3} \\
1 \frac{1}{4} \\
2 \frac{3}{4} \\
2 \frac{1}{4} \\
2 \frac{1}{3} \\
1 \frac{1}{8} \\
1 \frac{1}{10}\end{array}$ & $\begin{array}{l}0 \\
\frac{1}{2} \\
4 \frac{3}{2} \\
4 \frac{1}{2} \\
2^{\frac{1}{2}} \\
4^{\frac{1}{3}} \\
2^{1} \\
3 \frac{1}{2}^{1} \\
1 \frac{1}{4}\end{array}$ & $\begin{array}{l}\text { Inadequate cardiopulmonary bypass } \\
\text { Haemorrhage from" suture line" } \\
\text { Haemorrhage-coagulation defect } \\
\text { Anoxic heart lesion } \\
\text { Haemorrhage-suture line } \\
\text { Haemorrhage-suture line } \\
\text { Haemorrhage-coagulation defect } \\
\text { Haemorrhage-suture line } \\
\text { Low output syndrome } \\
\text { Haemorrhage-coagulation defect }\end{array}$ \\
\hline
\end{tabular}

${ }^{1}$ Breathed spontaneously after transplantation

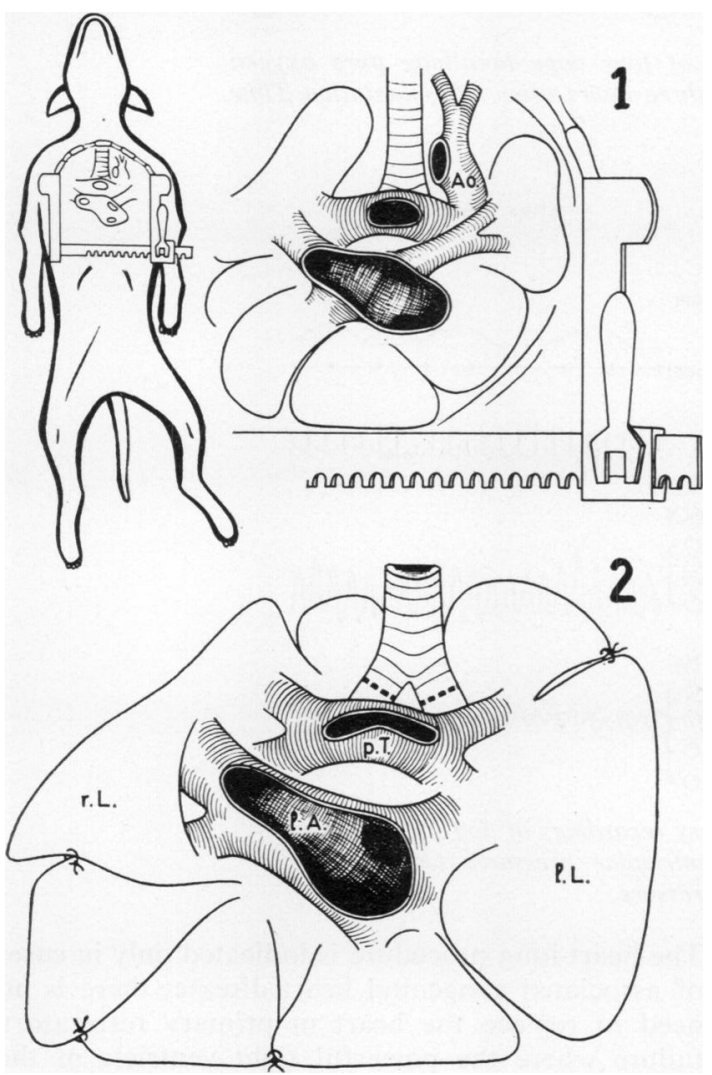

FIG. 2. Donor: (1) removal of heart; (2) harvested double-lung-block.

death of seven animals, fourth rough leaking anastomoses and three from post-perfusion coagulation defects. Two died of inadequate cardiopulmonary bypass. One developed anoxic heart damage at the beginning of the operation. Dog 75 eventually died in circulatory failure. The shortest cardiopulmonary bypass lasted $1 \mathrm{hr} 45 \mathrm{~min}$ (average $2 \mathrm{hr}$ $30 \mathrm{~min}$ ); the shortest ischaemia time of transplant
T A B LE II

BLOOD GASES AND PRESSURES IN SIX DOGS BREATHING PURE OXYGEN BEFORE AND AFTER DOUBLE-LUNG. PURE OXYGEN BEFORE AND AFTER DOUBLE-
BLOCK TRANSPLANTATION: MEAN \pm S.E.M.

\begin{tabular}{|c|c|c|c|c|}
\hline & & & Before & After \\
\hline $\begin{array}{l}\begin{array}{l}\text { Right } \\
\text { ventricle }\end{array} \\
\text { Aorta }\end{array}$ & $\begin{array}{c}\text { Pressure } \\
\left.\text { (cmH } \mathrm{H}_{2} \mathrm{O}\right) \\
\text { Pressure } \\
\text { (mmHg) } \\
\mathrm{Po}_{2}(\mathrm{mmHg}) \\
\mathrm{PcO}_{2}(\mathrm{mmHg}) \\
\text { pH }\end{array}$ & $\begin{array}{l}\text { Systolic } \\
\text { Diastolic } \\
\text { Systolic } \\
\text { Diastolic }\end{array}$ & $\begin{array}{c}27 \cdot 6 \pm 4 \cdot 9 \\
-0 \cdot 1 \pm 0 \cdot 1 \\
126 \pm 6 \\
83 \pm 3 \\
221 \pm 14 \cdot 7 \\
26 \cdot 1 \pm 4 \cdot 0 \\
7 \cdot 38 \pm 0 \cdot 05\end{array}$ & $\begin{array}{c}30 \cdot 0 \pm 7 \cdot 3 \\
-0 \cdot 1 \pm 0 \cdot 1 \\
107 \pm 9 \\
63 \pm 8 \\
82 \pm 8 \cdot 8 \\
37 \cdot 8 \pm 3 \cdot 8 \\
7 \cdot 36 \pm 0 \cdot 06\end{array}$ \\
\hline
\end{tabular}

was 1 hour $7 \mathrm{~min}$ (average $1 \mathrm{hr} 35 \mathrm{~min}$ ). In the six animals that breathed spontaneously after transplantation, spirograms were normal except for polypnea (Fig. 3). Table II shows moderate depression of gas exchange and systemic pressure after transplantation, with a normal right ventricular pressure; however, only diastolic systemic pressure was significantly lowered $(P<0.05)$. A typical sample record is given in Figure 4.

\section{COMMENTS}

Inadequate cardiopulmonary bypass was the direct cause of death in two animals. The rationale for using cardiopulmonary bypass when the operation can be performed without came from the desire to meet the requirements of a clinical case, rather than of a laboratory animal. If a dying patient could sustain such extensive surgery without cardiopulmonary bypass, he probably would not be in terminal failure. Indeed 7 of 23 patients submitted to pulmonary transplantation, mainly unilateral, required cardiopulmonary bypass (Wildevuur and Benfield, 1970). With more experience, double-lung transplantation could be performed within $1 \frac{1}{2} \mathrm{hr}$ of cardiopulmonary bypass; if one realizes that transplanted lungs escape all the effects of cardiopulmonary bypass, except the ischaemia, such a procedure should be tolerated in man. 


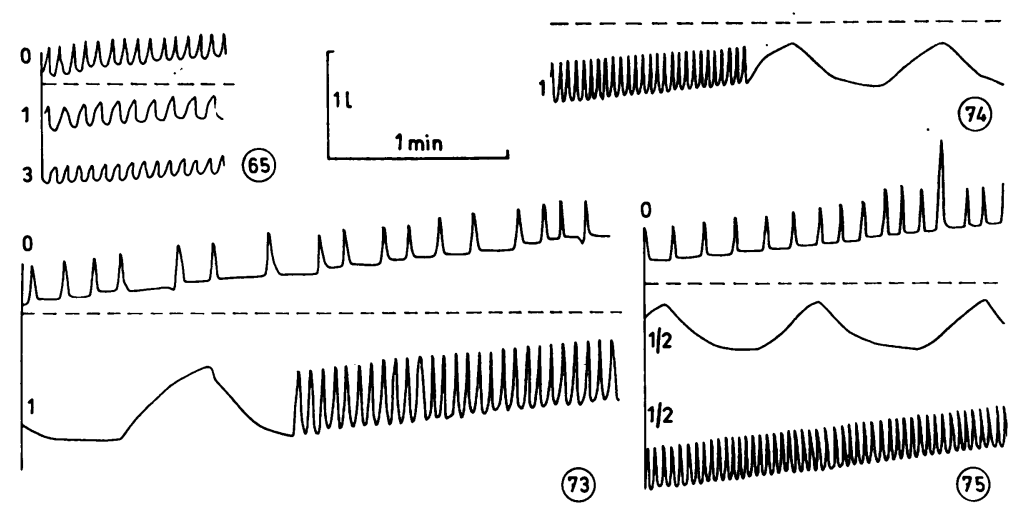

FIG. 3. Pre and postoperative spirograms of four dogs breathing pure oxygen before transplantation, one-half, one, and three hours after transplantation. Time scale applies to slow tracing segments.

Before transplant After transplant
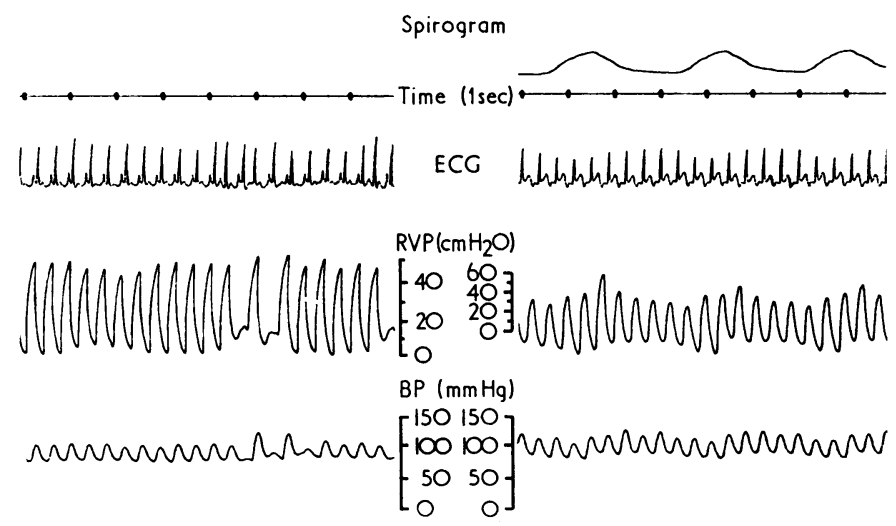

FIG. 4. Haemodynamic and respiratory recordings of dog 75. Marked influence of respiration on right ventricular pressures $(R V P)$ after transplantation. $B P=$ systemic blood pressure.

In each of the 10 animals whose heart sustained circulation after cardiopulmonary bypass, the haemodynamics appeared normal. This illustrates the absence of stenotic anastomoses in this type of transplantation. It is practically impossible to narrow such wide structures as the pulmonary trunk at its bifurcation and the entire left atrium. Unfortunately, the long suture lines are liable to bleed, especially in heparinized dogs, and this was the most frequent cause of death.

Alternative procedures for bilateral transplantation are the heart-lung, and separate right then left lung transplantation; both procedures have been tested by our team (Vanderhoeft et al., 1970b).
The heart-lung procedure is indicated only in cases of associated congenital heart disease; there is no need to replace the heart in primary respiratory failure where the powerful right ventricle of the patient would be useful. In addition, a denervated heart may not respond in normal fashion to high resistances, such as a failing rejected left ventricle, and could cause immediate pulmonary oedema. The longest survival of this 15 -year-old procedure in dogs was 11 days (Grinnan, Graham, Childs and Lower, 1970). Separate lung transplantation has proved feasible since Alican obtained eight longterm survivals (some of over nine months) out of 25 dogs (Alican, Cayirli, Isin, and Hardy, 
1971). However, Alican's procedure takes longer than a double-lung-block transplantation; there are two thoracotomies instead of one, and four vascular anastomoses instead of two. Though survivals in the present series were negligible, Table I suggests that, with further experience in canine cardiopulmonary bypass, the results will continue to improve.

We are indebted to F. Willems, B. Quadu, B. Vanderkelen, M. Saresky, R. Simpson, and to the nursing staff of the operating theatres for their help.

This work was supported by grants nos. 1176 and 1208 of the Belgian Fonds de la Recherche Scientifique Médicale.

\section{REFERENCES}

Alican, F., Cayirli, M., Isin, E., and Hardy, J. D. (1971). Left lung replantation with immediate right pulmonary artery ligation. Ann. Surg., 174, 34.

Demikhov, V. P. (1949). Homoplastic transplantation of the heart and lungs in warm blooded animals (dogs). Problems of Thoracic Surgery. Medgiz.

Grinnan, G. L. B., Graham, W. H., Childs, J. W., and Lower, R. R. (1970). Cardiopulmonary homotransplantation. J. thorac. cardiovasc. Surg., 60, 609.

Longmore, D. B., Cooper, D. K. C., Hall, R. W., Sekabunga, J., and Welch, W. (1969). Transplantation of the heart and both lungs. II. Experimental cardiopulmonary transplantation. Thorax, 24, 391.
Lower, R. R., Stofer, R. C., Hurley, E. J., and Shumway, N. E. (1961). Complete homograft replacement of the heart and both lungs. Surgery, 50, 842.

Stevens, P. M., Johnson, P. C., Bell, R. L., Beall, A. C., Jr. and Jenkins, D. E. (1970). Regional ventilation and perfusion after lung transplantation in patients with emphysema. New Engl. J. Med., 282, 245.

Vanderhoeft, P., de Francquen, Ph., Dubois, A., Lauvau, N., Rocmans, P., Willems, F., Kaufman, S., Brickman, L., and Nelson, R. (1970a). Anatomical basis of transmediastinal surgery on both lungs. Acta chir. Belg., 69, 149.

and $-(1970 b)$.

Radical transplant of the lungs. A study of different experimental procedures. Proceedings of the Societae Europaea Physiologiae Clinicae Respiratoriae. Berlin, November 1970.

Nemry, Ch., Willems, Fr., de Francquen, Ph., Pector, J-Cl., Rocmans, P., Lauvau, N., Marynen, L., Misone, P., Parmentier, R., and Bremer, A. (1969). Instabilité ventilatoire après transplantation d'un poumon gauche chez l'homme. Acta Chir. Belg., 68, 357.

- Rocmans, P., Nemry, Ch., de Francquen, Ph., Lauvau, N., and Pector, J-C. (1971). Left lung transplantation in patient with emphysema. Arch. Surg. 103, 505.

Veith, F. J., Sinha, S. B. P., Torres, M., and Richards, K. (1971). Bilateral simultaneous canine lung allotransplantation. Ann. Surg., 174, 48.

Vuillard, P., Gadot, P., Radice, P., Lamothe, P. X., Fischer, L., Belleville, J., Lesbroc, F., Wiesandenger, T., Brune, A., Falconnet, J., and Descotes, J. (1969). Homogreffe pulmonaire bilatérale simultanée chez le chien. Presse méd., 77, 1725.

Wildevuur, C. R., and Benfield, J. R. (1970). A review of 23 human lung transplantations by 20 surgeons. Ann. thorac. Surg., 9, 489. 